OPEN ACCESS

Edited by:

Rajesh Jha,

University of Hawaii at Manoa, United States

Reviewed by:

Julio Francisco Berrocoso, University of Hawaii at Manoa,

United States

Takeshi Ohkubo,

Ibaraki University, Japan

${ }^{*}$ Correspondence:

Hyun S. Lillehoj

hyun.lillehoj@usda.gov

Specialty section

This article was submitted to Animal Nutrition and Metabolism,

a section of the journal

Frontiers in Veterinary Science

Received: 13 February 2021

Accepted: 22 April 2021

Published: 20 May 2021

Citation:

Park I, Goo D, Nam H,

Wickramasuriya SS, Lee $K$,

Zimmerman NP, Smith AH,

Rehberger TG and Lillehoj HS (2021)

Effects of Dietary Maltol on Innate Immunity, Gut Health, and Growth Performance of Broiler Chickens Challenged With Eimeria maxima.

Front. Vet. Sci. 8:667425.

doi: 10.3389/fvets.2021.667425

\section{Effects of Dietary Maltol on Innate Immunity, Gut Health, and Growth Performance of Broiler Chickens Challenged With Eimeria maxima}

\author{
Inkyung Park ${ }^{1}$, Doyun Goo ${ }^{1}$, Hyoyoun Nam ${ }^{1}$, Samiru S. Wickramasuriya ${ }^{1}$, Kichoon Lee ${ }^{2}$, \\ Noah P. Zimmerman ${ }^{3}$, Alexandra H. Smith ${ }^{3}$, Thomas G. Rehberger ${ }^{3}$ and Hyun S. Lillehoj ${ }^{1 *}$ \\ ${ }^{1}$ Animal Bioscience and Biotechnology Laboratory, Beltsville Agricultural Research Center, Agricultural Research Service, \\ United States Department of Agriculture, Beltsville, MD, United States, ${ }^{2}$ Department of Animal Sciences, The Ohio State \\ University, Columbus, $\mathrm{OH}$, United States, ${ }^{3}$ Arm \& Hammer Animal and Food Production, Waukesha, WI, United States
}

Two studies were conducted to evaluate the effects of maltol as a postbiotic on innate immunity, gut health, and enteric infection. In the first study, an in vitro culture system was used to evaluate the effects of maltol on the innate immune response of chicken macrophage cells (CMC), gut integrity of chicken intestinal epithelial cells (IEC), anti-parasitic activity against Eimeria maxima, and differentiation of quail muscle cells (QMC) and primary chicken embryonic muscle cells (PMC). All cells seeded in the 24-well plates were treated with maltol at concentrations of $0.1,1.0$, and $10.0 \mu \mathrm{g}$. CMC and IEC were stimulated by lipopolysaccharide to induce an innate immune response, and QMC and PMC were treated with 0.5 and $2 \%$ fetal bovine serum, respectively. After $18 \mathrm{~h}$ of incubation, pro-inflammatory cytokines, tight junction proteins (TJPs), and muscle cell growth markers were measured. In the second study, the dietary effect of maltol was evaluated on disease parameters in broiler chickens infected with E. maxima. Eighty male 1-day-old broiler chickens were allocated into the following four treatment groups: (1) Control group without infection, (2) Basal diet with E. maxima, (3) High maltol $(\mathrm{HI} ; 10.0 \mathrm{mg} / \mathrm{kg}$ feed) with E. maxima, and (4) Low maltol (LO; $1.0 \mathrm{mg} / \mathrm{kg}$ feed) with E. maxima. Body weights (BW) were measured on days $0,7,14,20$, and 22 . All chickens except the CON group were orally infected with $10^{4} \mathrm{E}$. maxima per chicken on day 14. Jejunum samples were collected for gut lesion scoring, and the gene expression of cytokines and TJPs. Data was analyzed using PROC MIXED in SAS. In vitro, maltol not only increased TJPs in IEC and cytokines in the LPS-stimulated CMC but also showed direct cytotoxicity against sporozoites of E. maxima. In vivo, the HI group improved the BW, reduced the gut lesion scores and fecal oocyst shedding, and decreased jejunal TNFSF15 and IL-1 $1 \beta$ expression in E. maxima-infected chickens. In conclusion, these results demonstrate the beneficial effects of dietary maltol in the enhancement of growth performance, gut health, and coccidiosis resistance and the applicability of maltol as a postbiotic for the replacement of antibiotic growth promoters in commercial poultry production.

Keywords: broiler chickens, Eimeria maxima, growth performance, gut health, maltol, metabolites, postbiotics 


\section{INTRODUCTION}

Eimeria spp. are the etiologic agents of avian coccidiosis, an intestinal disease responsible for an economic loss of more than $\$ 3$ billion per year $(1,2)$. Increasing implementation of antibioticfree poultry production system in the U.S. is making the control of some enteric pathogens such as coccidiosis-causing Eimeria species and necrotic enteritis-inducing Clostridium perfringens strains challenging (3). Because coccidiosis is a primary risk factor for necrotic enteritis, it is desirable if alternatives to antibiotics can reduce Eimeria as well as Clostridium perfringens (4). Development of antibiotic alternatives is a priority for the animal agriculture industry to maintain the growth performance and health of food-producing animals without losing productivity in the post-antibiotic era (5). Although the mode of action of antibiotic growth promoters remains debatable, dietary antibiotic growth promoters undoubtedly influence the gut microbiota, host immune status, and other host physiological responses (2-4). Therefore, developing antibiotic alternatives that can manipulate gut microbiota to promote host growth and health is a logical goal for the animal industry $(6,7)$. Considering this goal, metagenomics has been conducted in several studies to analyze the entire population of gut microbiota based on various research areas such as nutrition, physiology, and immunology $(8,9)$. Although amplicon sequencing using metagenomics enables comprehensive characterization of the taxonomic composition of the gut microbiome, it is impossible to obtain direct evidence of the microbial functions related to the gut microbial community $(10,11)$. Hence, the critical next step for gut microbiome studies is a transition from gene/genome-centric analysis to mechanism-centric techniques by integrating omics data with experimental results $(12,13)$. Thus, mainstream studies on the gut microbiota include adoption of a combination of analytical approaches, such as metatranscriptomics, meta-proteomics, and metabolomics, together with established metagenomics (14-17). With the development of the "omics" technology related to the investigation of gut health, the term "postbiotics" was coined and defined as a novel class of feed additives that are generally produced by beneficial gut microbes and which exert a positive influence on the host health (18). In our previous study (19), dietary feeding of the Bacillus subtilis 1781 strain induced the alteration of chicken gut metabolites which was associated with the growth- and immune-promoting effects of dietary B. subtilis 1781 strain in chickens. Among the highly altered gut metabolites, maltol was one of the significantly increased metabolites that we selected for further studies since maltol mediates various physiological functions associated with anti-oxidant (20) and anti-carcinogen (21) activities and reduces inflammatory responses (22).

We hypothesized that maltol could be a good candidate as a growth-promoting postbiotic because its expression was highly upregulated in the gut of chickens fed with a diet supplemented with the B. subtilis strain 1781, which influenced the intestinal immune response, gut barrier integrity, and growth-promotion in fast-growing chickens. Therefore, the objectives of the present study were: (1) the in vitro evaluation of effects of maltol on the host innate immune response using chicken macrophage cells
(CMC), on the barrier integrity on chicken intestinal epithelial cells (IEC), on anti-coccidial ability against Eimeria maxima, and on myogenic differentiation of quail muscle cells (QMC) and primary chicken embryonic muscle cells (PMC); and (2) the in vivo characterization of the dietary maltol on growth performance, intestinal immunity, and epithelial integrity in young broiler chickens challenged with E. maxima. These studies will provide information on the mechanisms through which the alteration of gut metabolites generated by dietary direct-fed microbes exerts beneficial physiological changes on the host.

\section{MATERIALS AND METHODS}

\section{Experiment 1: In vitro Study}

Culture of Chicken Intestinal Epithelial Cells (IEC) and Chicken Macrophage Cells (CMC)

IEC $\left(2 \times 10^{5} / \mathrm{mL}, 8 \mathrm{E} 1\right.$; MicroMol GmbH, Karlsruhe, Germany) and CMC $\left(2 \times 10^{5} / \mathrm{mL}, \mathrm{HD} 11\right)$ (23) were seeded in 24-well plates and grown in the Dulbecco's modified Eagle medium (DMEM)/F-12 (Hyclone, Logan, UT) supplemented with 1\% penicillin/streptomycin (Gibco, Grand Island, NY, USA) and $10 \%$ heat-inactivated fetal bovine serum (FBS, Hyclone), and incubated at $41^{\circ} \mathrm{C}$ in a humidified atmosphere with $5 \% \mathrm{CO}_{2}$ for $24 \mathrm{~h}$ for cell adhesion. After $24 \mathrm{~h}$, lipopolysaccharide (LPS, Sigma-Aldrich, St. Louis, MO) at a concentration of $1.0 \mu \mathrm{g} / \mathrm{mL}$ and maltol (Sigma-Aldrich) at concentrations of $0.0,0.1,1.0$, and $10.0 \mu \mathrm{g} / \mathrm{mL}$ were added to each well in the 24 -well plates. After $18 \mathrm{~h}$, all cells were harvested in lysis buffer (QIAGEN, Hilden, Germany) with 2-mercaptoethanol (Sigma-Aldrich). RNA was extracted using QIAcube (QIAGEN) for performing quantitative real-time polymerase chain reaction (qRT-PCR) analysis. All experiments were replicated more than three times independently.

\section{Anticoccidial Assay Against E. maxima}

Sporozoites of E. maxima were obtained by excystation of sporulated oocysts as described (24). Briefly, fresh sporulated oocysts were disrupted with $0.5-\mathrm{mm}$ glass beads for $10 \mathrm{~s}$ using the Mini-Beadbeater (BioSpec Products, Bartlesville, OK). The released sporocysts were washed in chilled Hanks' balanced salt solution (Hyclone) and treated with $0.25 \%$ trypsin and $0.014 \mathrm{M}$ taurocholic acid (Sigma-Aldrich) for $1 \mathrm{~h}$ to release sporozoites. Sporozoites $\left(2.5 \times 10^{5}\right)$ were added to each well of a 96-well plate. Chicken NK-lysin (Genscript, Piscataway, NJ) at concentrations of $1.0,10$, and $100 \mu \mathrm{g} / \mathrm{mL}$ were used as positive controls. Three different maltol doses, low $(0.1 \mu \mathrm{g} / \mathrm{mL})$, medium $(1.0 \mu \mathrm{g} / \mathrm{mL})$, and high $(10 \mu \mathrm{g} / \mathrm{mL})$, were used to treat freshly prepared live sporozoites and incubated at $41^{\circ} \mathrm{C}$ for $3 \mathrm{~h}$. Fluorescent dye (AO/PI staining solution, Nexcelom Bioscience LLC, Lawrence, MA) was added to each mixture in a 1:1 ratio, and live sporozoites were counted using a cell counting chamber (Nexcelom Bioscience LLC). All experiments were replicated more than three times independently.

\section{QMC Culture}

QMCs $\left(2 \times 10^{5} / \mathrm{mL}\right)$ were seeded in 24-well plates, as previously described (20) in Medium 199 (Hyclone) containing 10\% 
FBS and $1 \%$ penicillin/streptomycin until $70 \%$ confluence was achieved. Media in 12-wells were replaced by Medium 199 containing $0.5 \% \mathrm{FBS}$ with $1 \%$ penicillin/streptomycin to induce cell differentiation, and in the remaining 12-wells of the same plate, media were replaced by a basic Medium 199 containing $10 \%$ FBS to maintain cell proliferation. Maltol at concentrations of $0.0,0.1,1.0$, and $10.0 \mu \mathrm{g} / \mathrm{mL}$ was added to each well in the 24well plates. After incubation at $41^{\circ} \mathrm{C}$ in a humidified atmosphere with $5 \% \mathrm{CO}_{2}$ for $18 \mathrm{~h}$, all cells were harvested in lysis buffer with 2-mercaptoethanol. RNA was extracted using QIAcube for performing qRT-PCR analysis. All experiments were replicated more than three times independently.

\section{Primary Chicken Embryonic Muscle Cell (PMC) Culture}

Eggs for the embryo were obtained from Moyer's hatchery (Quakertown, PA). The PMC culture was modified based on the method described by Hassan et al. (25). Briefly, eggs were incubated at $41^{\circ} \mathrm{C}$ and $80 \%$ humidity. The pectoralis major region of the embryos was extracted at 13 days; it was minced and digested with $0.05 \%$ trypsin-EDTA (SigmaAldrich) at $37^{\circ} \mathrm{C}$ for $20 \mathrm{~min}$. The primary cells were washed 2-3 times with Hanks balanced salt solution (Sigma-Aldrich) and seeded $\left(2 \times 10^{5} / \mathrm{mL}\right)$ in 24 -well plates. Primary muscle cells were incubated in DMEM (Hyclone) containing 10\% FBS and $1 \%$ penicillin/streptomycin until $70 \%$ confluence was achieved. Media in 12-wells were replaced by DMEM containing 2\% FBS with $1 \%$ penicillin/streptomycin to induce cell differentiation, and in the remaining 12-wells of the same plate, media were replaced by basic DMEM containing 10\% FBS to maintain cell proliferation. Maltol at concentrations of $0.0,0.1,1.0$, and $10.0 \mu \mathrm{g} / \mathrm{mL}$ was added to each well in the 24 -well plates. After incubation at $41^{\circ} \mathrm{C}$ in a humidified atmosphere with $5 \% \mathrm{CO}_{2}$ for $18 \mathrm{~h}$, all cells were harvested in lysis buffer with 2-mercaptoethanol. RNA was extracted using QIAcube for qRT-PCR analysis. All experiments were replicated more than three times.

\section{Analysis of Cytokines, Tight Junction (TJ) Proteins, and Markers of Muscle Cell Growth by qRT-PCR}

The levels of pro-inflammatory cytokines (IL-1 $\beta$, IL-6, and IL-8) were determined in IEC and CMC using extracted RNA samples. For analysis of TJ proteins (occludin, ZO-1, and MUC2), qRT-PCR was conducted using RNA samples extracted from IEC without LPS stimulation. Proliferation and differentiation markers of muscle cells, Pax7 and MyoG, were measured using samples obtained from QMC and PMC. Total RNA was extracted using QIAcube. RNA was eluted in 30 $\mu L$ RNase-free water, and the concentration and yield were determined using the NanoDrop ND-1000 spectrometer (NanoDrop Technology, Wilmington, DE, USA). A $1-\mu$ g aliquot of total RNA was reverse-transcribed to cDNA using the QuantiTect Reverse Transcription Kit (Qiagen), and all cDNA samples were diluted 1:10 with RNase-free water for subsequent analysis. qRT-PCR was performed using the Agilent Mx3000 P QPCR System (Agilent Technologies, Santa Clara, CA) and the Brilliant SYBR Green qRT-PCR Master Mix (Stratagene, La Jolla, CA).
Oligonucleotide primer sequences and accession numbers used for chicken cytokines are listed in Table 1. Standard curves were generated using $\log 10$ diluted standard samples of RNA to calculate the amplification efficiency, and the levels of individual transcripts were normalized to those of $\beta$-actin using the Q-gene software program (26).

\section{Experiment 2: In vivo Study}

All animal experiments were approved by the Beltsville Agricultural Research Center Institutional Animal Care and Use Committee (\#19-018). Figure 1 depicts the schematic outline of the experimental design used for this study.

\section{Chickens and Experimental Design}

A total of 80 newly hatched (Ross 708) male broiler chickens at 0 days of age were purchased from Longenecker's hatchery (Elizabethtown, PA). The day after the chickens arrived at the Beltsville ARS facility, they were weighed to perform adjustments to obtain the same body weight (BW) per treatment and allocated to four dietary treatments in a randomized complete block design. The dietary treatments included provision of a cornand soybean meal-based (basal) diet without infection (CON, Table 2), basal diet with E. maxima infection (NC), maltol (Sigma-Aldrich) at $10.0 \mathrm{mg} / \mathrm{kg}$ feed (HI), and maltol at $1.0 \mathrm{mg} / \mathrm{kg}$ feed (LO) Each treatment group was allocated into two cages with ten chickens per cage $\left(0.65 \times 0.75 \mathrm{~m}^{2}\right)$. The chickens were provided with ad libitum access to water and feed throughout the experimental period. A schematic outline of the experimental design is shown in Figure 1.

\section{Determination of BW}

Chickens were weighed on days 1, 7, 14, 20, and 22 for the computation of BW and average daily gain (ADG). Dead chickens were removed and weighed daily to perform adjustments for the growth data.

\section{Oral Infection With E. maxima}

All chickens, except for those in the CON group, were orally infected with $E$. maxima $\left(1.0 \times 10^{4}\right.$ oocysts/bird; Beltsville strain 41A) on day 14 as previously described (27). The purity of the infected E. maxima was confirmed by conducting a DNA genotyping test (28).

\section{Collection of Intestinal Samples}

Two chickens from each cage with a medium BW were euthanized by cervical dislocation on day 20 , and their intestines were removed for further analysis. From each intestine, a small section $(2 \mathrm{~cm})$ of the jejunum without contents was collected aseptically and stored in RNAlater ${ }^{\circledR}$ (Invitrogen, Carlsbad, CA) at $-20^{\circ} \mathrm{C}$ until subsequent analysis.

\section{Gut Lesion Scoring}

Using the $15-\mathrm{cm}$ long mid jejunum sample, gut lesion scoring was performed on day 20. Lesions were scored on a scale from 0 (none) to 4 (high) by four independent 
TABLE 1 | Oligonucleotide primer sequences for qRT-PCR.

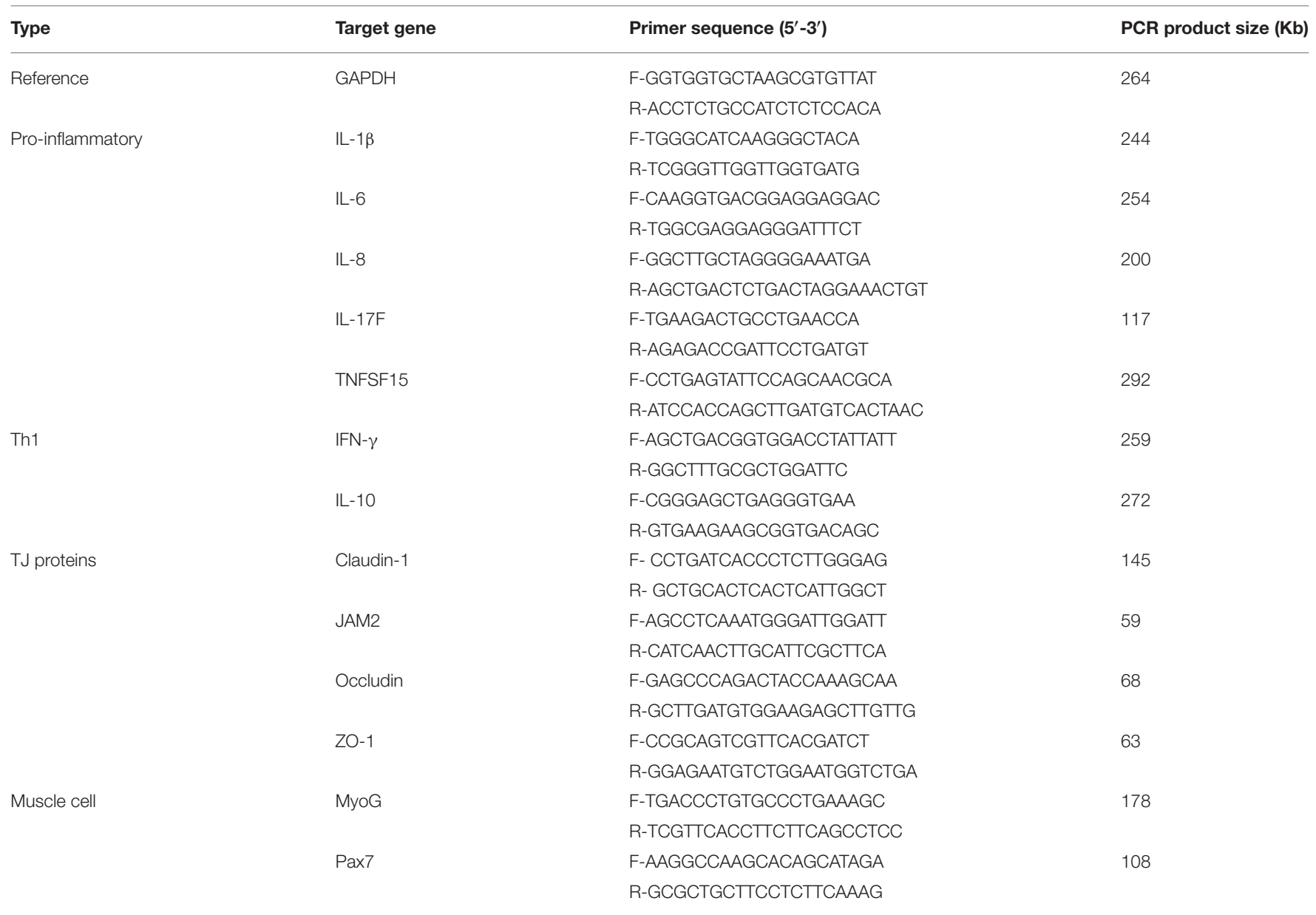

Th, Thelper cells; TJ, tight junction.

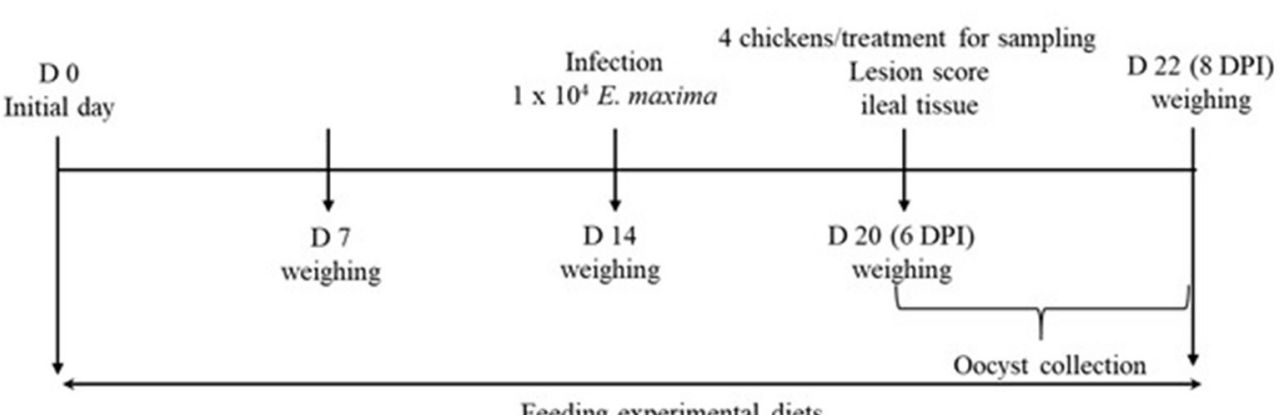

Feeding experimental diets

FIGURE 1 | Schematic outline of the experimental design in experiment 2.

observers in a blinded manner, as per methods described previously (29).

\section{Fecal Oocyst Shedding}

From days 20-22 (6-8 days post-infection: dpi), fecal samples were collected and the number of sporulated oocysts was determined as previously described (30) using the McMaster chamber according to the following formula:

Total oocysts/chicken $=[$ oocyst count $\times$ dilution factor $\times$ (fecal sample volume/counting chamber volume)]/number of chickens per cage. 
TABLE 2 | Ingredient composition of basal diet (as feed? basis, \%, unless otherwise indicated).

\begin{tabular}{ll}
\hline Ingredients (\%) & Basal diet \\
\hline Corn & 55.78 \\
Soybean meal & 37.03 \\
Soybean oil & 2.97 \\
Dicalcium phosphate & 1.80 \\
Calcium carbonate & 1.51 \\
Salt & 0.38 \\
Poultry Vit Mix ${ }^{\text {a }}$ & 0.22 \\
Poultry Mineral Mix ${ }^{b}$ & 0.15 \\
DL-Methionine & 0.10 \\
Choline-chloride, 60\% & 0.06 \\
Total & 100 \\
Calculated values (\%) & \\
CP, \% & 24.00 \\
Ca, \% & 1.20 \\
AP, \% & 0.51 \\
Total Lys, \% & 1.40 \\
Total Met, \% & 0.49 \\
Total Cys + Met, \% & 0.80 \\
ME, Mcal/kg & 3.5 \\
\hline
\end{tabular}

a Vitamin mixture provided the following nutrients per $\mathrm{kg}$ of diet: vitamin $A, 2,000 \mathrm{U}$; vitamin D3, 22 U; vitamin E, $16 \mathrm{mg}$; vitamin $\mathrm{K}, 0.1 \mathrm{mg}$; vitamin B1, $3.4 \mathrm{mg}$; vitamin B2, $1.8 \mathrm{mg}$; vitamin B6, $6.4 \mathrm{mg}$; vitamin B12, $0.013 \mathrm{mg}$; biotin, $0.17 \mathrm{mg}$; pantothenic acid, $8.7 \mathrm{mg}$; folic acid, $0.8 \mathrm{mg}$; niacin, $23.8 \mathrm{mg}$.

${ }^{b}$ Mineral mixture provided the following nutrients per $\mathrm{kg}$ of diet: Fe, $400 \mathrm{mg} ; \mathrm{Zn}, 220 \mathrm{mg}$; Mn, $180 \mathrm{mg}$; Co, $1.3 \mathrm{mg}$; Cu, $21 \mathrm{mg}$; Se, $0.2 \mathrm{mg}$. CP, crude protein; AP, available phosphorus.

\section{Isolation of RNA and Reverse Transcription}

Total RNA was isolated from jejunum samples that were stored in RNAlater ${ }^{\circledR}$ according to the manufacturer's recommendations. Approximately $50 \mathrm{mg}$ of the jejunal tissue was homogenized in $1 \mathrm{~mL}$ of TRIzol (Invitrogen) using a hand-held homogenizer (TissueRuptor; Qiagen). Chloroform was added to the homogenized sample. The samples were centrifuged at 12,000 $\times g$ for $15 \mathrm{~min}$ at $4{ }^{\circ} \mathrm{C}$ for phase separation. RNA present in the colorless upper aqueous phase was then precipitated using $100 \%$ isopropanol (Sigma-Aldrich). The RNA pellet was washed with $75 \%$ ethanol (Sigma-Aldrich), air-dried, and re-suspended in RNase-free water (Invitrogen). The quantity of RNA was assessed using the NanoDrop (ND-1000) spectrophotometer (NanoDrop Products, Wilmington, DE) according to the absorbance at $260 \mathrm{~nm}$. RNA purity was evaluated based on the OD260/OD280 ratio. Total RNA $(1 \mu \mathrm{g})$ was then reverse-transcribed to cDNA using the QuantiTect ${ }^{\circledR}$ reverse transcription kit (Qiagen). Briefly, the RNA sample was incubated with genomic DNA wipeout buffer at $42^{\circ} \mathrm{C}$ for $2 \mathrm{~min}$ to remove any genomic DNA contamination. Reverse transcription (RT) of the genomic DNA-depleted sample was performed by the addition of the Quantiscript Reverse Transcriptase, Quantiscript RT buffer, and RT primer mix (Qiagen). The reaction was performed in a thermal cycler (Mastercycler ${ }^{\circledR}$ EP Gradient S; Eppendorf, Hauppauge, NY). The cycling conditions were $42^{\circ} \mathrm{C}$ for $30 \mathrm{~min}$, followed by reverse transcriptase inactivation at $95^{\circ} \mathrm{C}$ for $3 \mathrm{~min}$. The cDNA samples were divided into aliquots and stored at $-20^{\circ} \mathrm{C}$.

\section{Gene Expression Analysis by qRT-PCR}

The oligonucleotide primer sequences used for qRT-PCR are listed in Table 1. The expression of various cytokines and intestinal TJ proteins was evaluated in the jejunum, including IL$1 \beta$, IL-6, IL-10, IL-17F, IFN- $\gamma$, TNFSF15, JAM2, occludin, ZO-1, and claudin-1. Glyceraldehyde-3-phosphate dehydrogenase was used as the reference gene. Amplification and detection were performed using the Stratagene Mx3000P qPCR system (Agilent Technologies Inc.) and $\mathrm{RT}^{2}$ SYBR Green qPCR master mix (Qiagen). Each sample was analyzed in triplicate, and nonspecific primer amplification was assessed via the inclusion of no-template controls. Standard curves were generated using $\log 10$ diluted standards of RNA, and the levels of individual transcripts were normalized to those of Glyceraldehyde-3phosphate dehydrogenase in the Q-gene program (26).

\section{Statistical Analysis}

In vitro data for each response were analyzed using the Proc GLM in SAS (SAS Inc., Cary, NC). In vivo data were analyzed using a mixed model (PROC MIXED) in SAS. Each chicken was considered an experimental unit. The results are shown as least squares mean values and pooled standard error of the mean. Probability values $<0.05$ were considered significantly different. In cases where the overall effect was significant, the mean values were compared in a pairwise manner (PDIFF option).

\section{RESULTS}

\section{Experiment 1: In vitro Studies} Effect of Maltol on the Gene Expression of Biomarkers Associated With Inflammation and Gut Integrity in Chicken Epithelial Cells

LPS stimulation of IEC increased $(P=0.041)$ IL-1 $\beta$ levels $(0.9$ to 1.4 -fold) compared to those in the control without LPS treatment, whereas maltol alone did not change the IL- $1 \beta$ levels (Figure 2A). For IL-6, LPS stimulation increased $(P=0.038)$ IL-6 levels (1.3- to 4.1-fold) independent of maltol treatment compared to those of the groups without LPS stimulation (Figure 2B). With LPS treatment, maltol increased $(P<0.002)$ IL-6 levels in a dose-dependent manner from 0.1 (2.32- to 3.7fold) to $1.0 \mu \mathrm{g} / \mathrm{mL}$ (2.3- to 5.7 -fold) compared to those of the LPS control (maltol at $0.0 \mu \mathrm{g} / \mathrm{mL}$ ). Maltol increased occludin (Figure 3A, 1.0- to 3.4-fold) and MUC2 (Figure 3C, 1.0- to 1.9fold) gene expression $(P<0.001)$ at a dose of $1.0 \mu \mathrm{g} / \mathrm{mL}$. Maltol also induced higher $(P<0.001) \mathrm{ZO}-1$ levels $(1.0$ - to 2.6-fold $)$ from 0.1 to $10.0 \mu \mathrm{g} / \mathrm{mL}$ in IEC than those in the control without maltol (Figure 3B).

\section{Effect of Maltol on Pro-inflammatory Responses of $\mathrm{CMC}$}

LPS stimulation increased $(P<0.001)$ IL-1 $\beta$ levels $(1.5$ - to 9.1fold) in CMC compared to those in the groups without LPS treatment, and maltol treatment further increased $(P<0.001)$ 

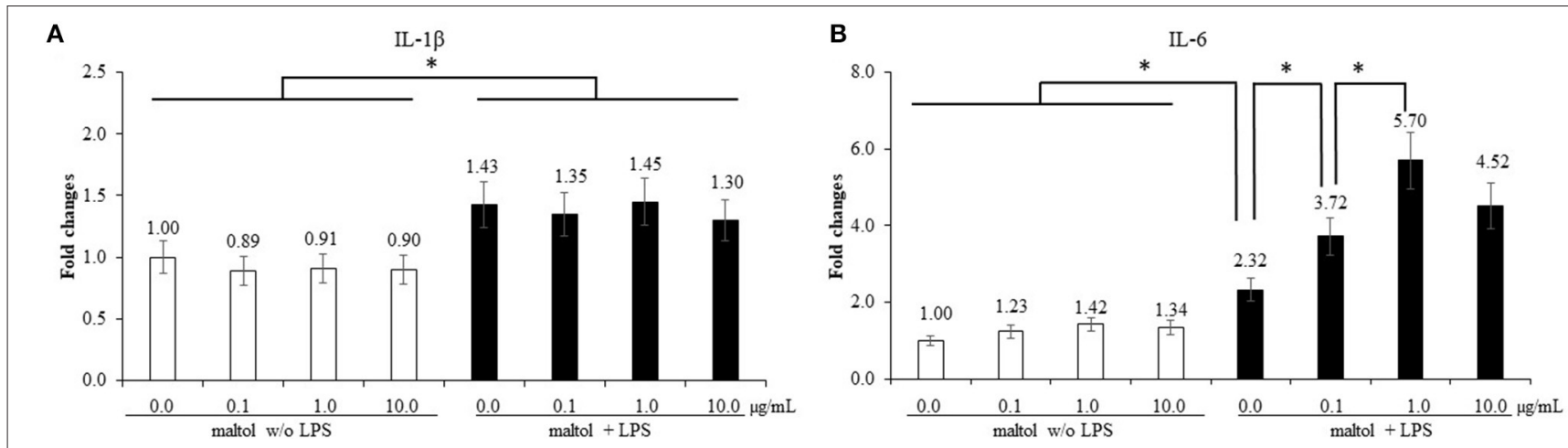

FIGURE 2 | Secretion of pro-inflammatory cytokines in chicken epithelial cells (IEC) by LPS and maltol. Each bar represents the mean \pm SEM ( $n=3$ ). Transcript levels of the cytokines were measured using quantitative RT-PCR and normalized to GAPDH transcript levels. Significant results are marked as * $(P<0.05)$. LPS, lipopolysaccharide.

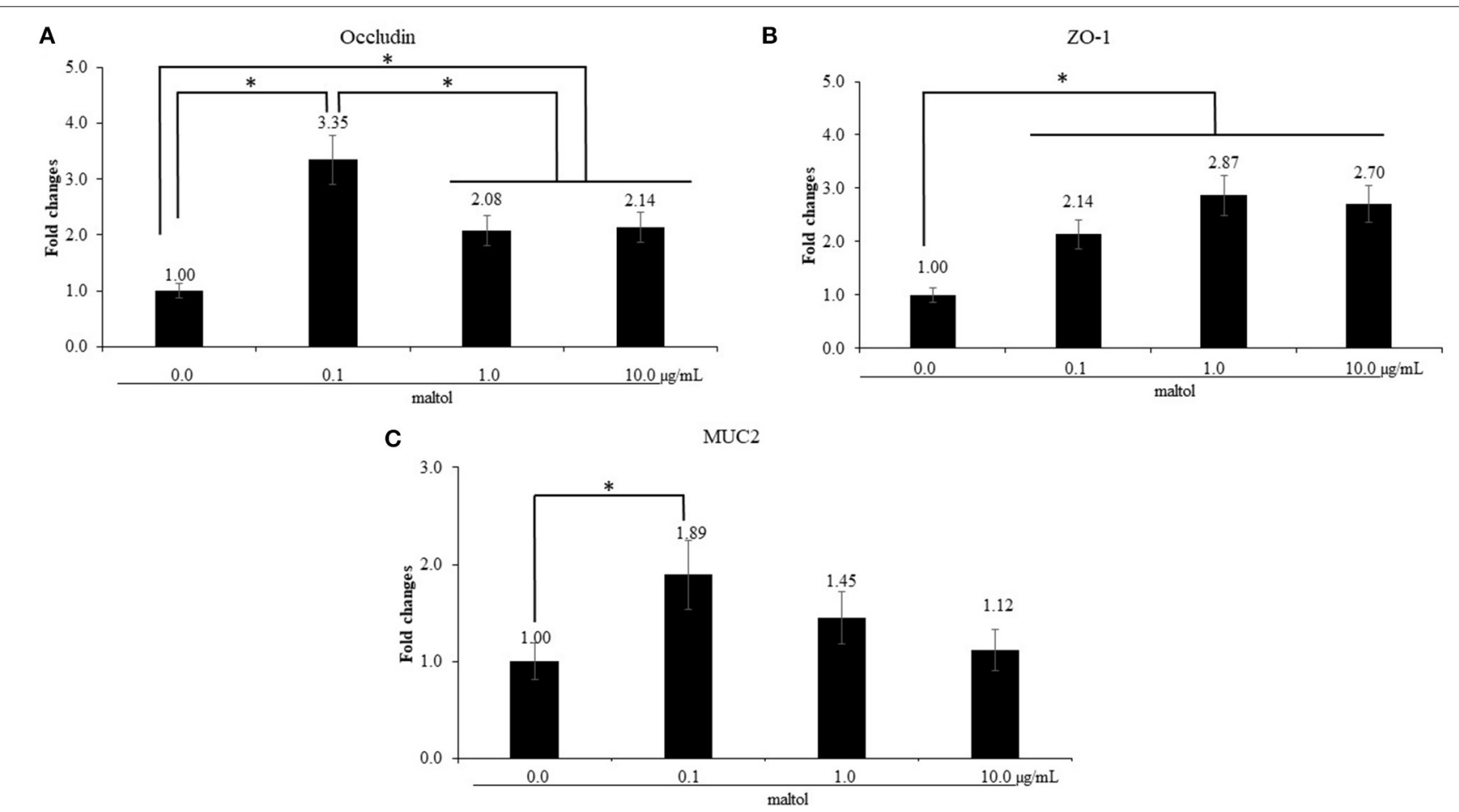

FIGURE 3 | Alteration of tight junction proteins and mucin in chicken epithelial cells (IEC) by maltol. Each bar represents the mean \pm SEM ( $n=3$ ). Transcript levels of the tight junction proteins were measured using quantitative RT-PCR and normalized to GAPDH transcript levels. Significant results are marked as * $(P<0.05)$.

IL-1 $\beta$ levels from 9.1- to 28.4-fold (Figure 4A). In groups without LPS stimulation, maltol increased IL-6 levels from 0.1 to $10.0 \mu \mathrm{g} / \mathrm{mL}(P<0.042)(1.0$ - to 2.5 -fold $)$ compared to those in the control (Figure 4B). LPS stimulation increased $(P=0.038)$ IL-6 levels (2.1- to 4.5-fold) compared to those of groups without LPS stimulation. Among the LPS groups, maltol at a dose of $0.1 \mu \mathrm{g} / \mathrm{mL}$ increased $(P=0.028)$ IL-6 levels $(4.2$ - to 5.8 -fold) compared to those in the groups with LPS administration without maltol (Figure 4B). Furthermore, LPS stimulation increased $(P$ $<0.001)$ IL-8 levels (2.4- to 77-fold) in CMC compared to those in non-LPS groups (Figure 4C). Among the LPS groups, maltol at a dose of $0.1 \mu \mathrm{g} / \mathrm{mL}$ increased $(P=0.048)$ IL- 8 levels (77- to 270-fold) compared to those in the LPS control without maltol treatment.

\section{Anticoccidial Activity of Maltol Against Sporozoites of E. maxima}

Chicken NK-lysin which was used as a positive control decreased $(P<0.001)$ the survival rate of sporozoites of E. maxima in a dose-dependent manner by $12-48 \%$ compared to that in 


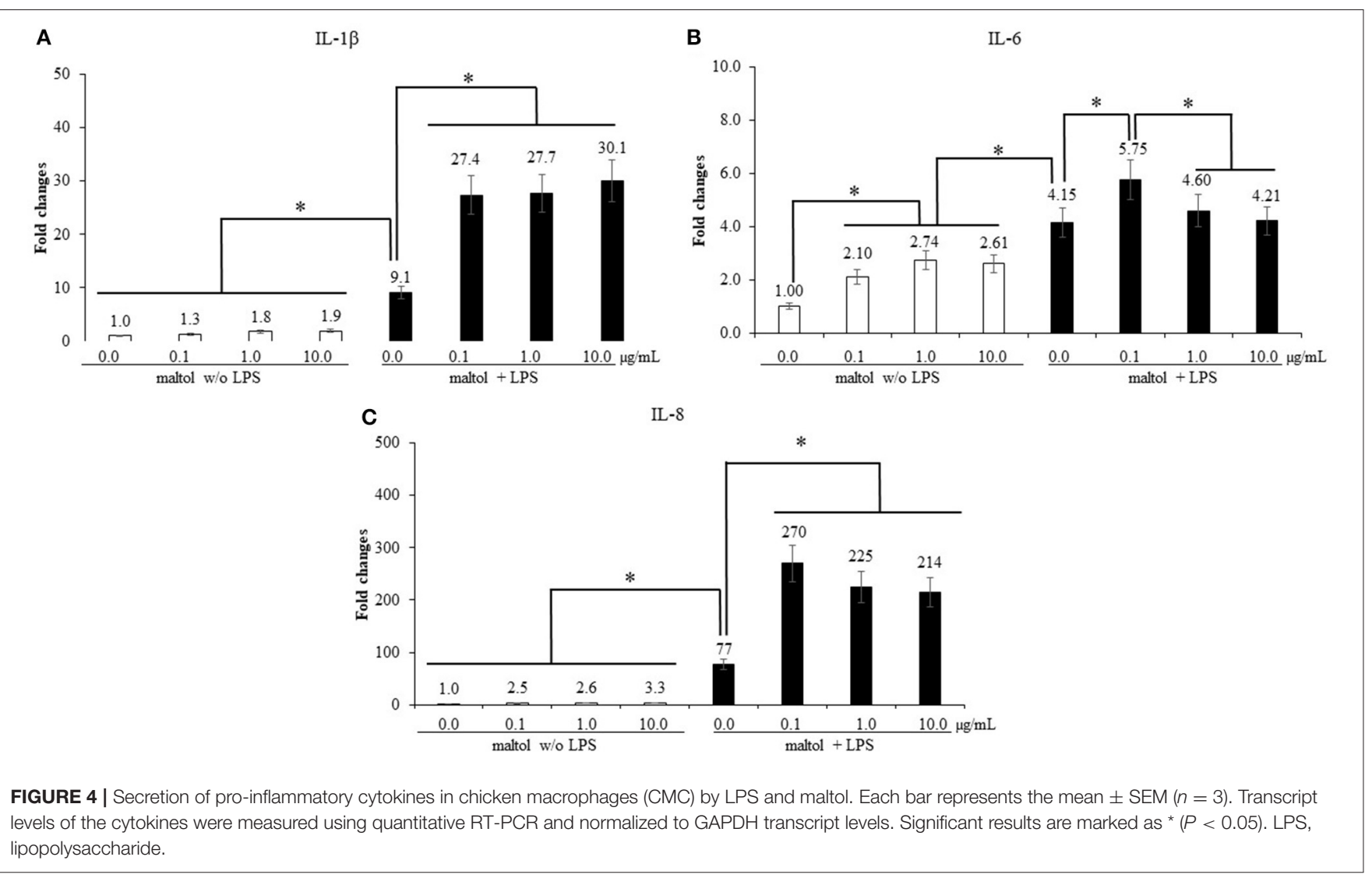

the CON group (Figure 5). Maltol showed a dose-dependent decrease of sporozoites of E. maxima by $36-59 \%$ compared to that in the CON group.

\section{Effect of Maltol on the Proliferation and Differentiation of QMCs and PMCs}

The treatment using $0.5 \%$ FBS without maltol did not change $(P>0.05,1.0-1.2)$ Pax7 levels of QMCs compared to those observed after treatment using 10\% FBS (Figure 6). However, maltol at a dose of $10.0 \mu \mathrm{g} / \mathrm{mL}$ increased $(P<0.05)$ Pax7 levels regardless of the FBS concentration compared to those in the corresponding control groups (1.0-1.4 in 10\% FBS and 1.2-2.3 in $0.5 \% \mathrm{FBS})$. In contrast, in the treatment groups using $0.5 \%$ FBS, maltol increased $(P<0.05)$ the MyoG levels $(1.2-3.6)$ of QMCs regardless of the dose of maltol used compared to those observed after treatment using 10\% FBS. In PMC, maltol at a dose of $10.0 \mu \mathrm{g} / \mathrm{mL}$ increased Pax7 levels (1.0-1.6) in the group subjected to a treatment using $10 \%$ FBS $(P<0.05)$ compared to those in the other groups. However, MyoG levels of PMCs did not change $(P>0.05)$ with respect to the maltol dose or FBS concentration used.

\section{Experiment 2: In vivo Studies}

\section{Growth Performance of Chickens}

The initial BW did not show significant differences among the experimental groups $(P=0.998$; Table 3$)$. In the absence of challenge infection, treatment with dietary maltol did not significantly change $(P>0.05)$ the BW of chickens until day 14 regardless of the dose of maltol used compared to that of the control group, even though the HI and LO groups increased the BW of chickens numerically compared to those in the CON and NC groups. E. maxima infection decreased $(P<0.001)$ the BW of chickens at $6 \mathrm{dpi}(860-743 \mathrm{~g})$ and $8 \mathrm{dpi}(1,017-763 \mathrm{~g})$ compared to that of the CON group. The HI group increased the BW of chickens at $6 \mathrm{dpi}(P=0.040,743-794 \mathrm{~g})$ and 8 dpi $(P<0.001,763-934 \mathrm{~g})$ compared to that of the NC group. The LO group also increased $(P=0.015)$ the BW of chickens (763-842 g) at $8 \mathrm{dpi}$ compared to that of the NC group. Before infection, the ADG of the chickens fed with diets supplemented with maltol did not differ $(P>0.05)$ from that of the CON group, although the ADGs of chickens fed with diets supplemented with maltol increased numerically regardless of the dose administered. E. maxima-infected chickens (NC group) presented with lower ADG at 0 to $6 \mathrm{dpi}(P<0.001,66.5-47.7 \mathrm{~g})$ compared to that of the uninfected CON group. The HI group increased the ADG of the infected chickens at $0-6 \mathrm{dpi}(P=0.011,47.7-53.7 \mathrm{~g})$. During the entire infection period ( $0-8 \mathrm{dpi})$, the HI $(P<0.001,38.2-57.8 \mathrm{~g})$ and LO $(P=0.002,38.2-46.9 \mathrm{~g})$ groups increased the ADG of chickens compared to that of the NC group, which was decreased by E. maxima infection.

\section{Intestinal Lesion Scores and Fecal Oocyst Shedding}

E. maxima infection increased $(P<0.001)$ the gut lesion scores (0.4-1.5) of the jejunum compared to that of the control group 


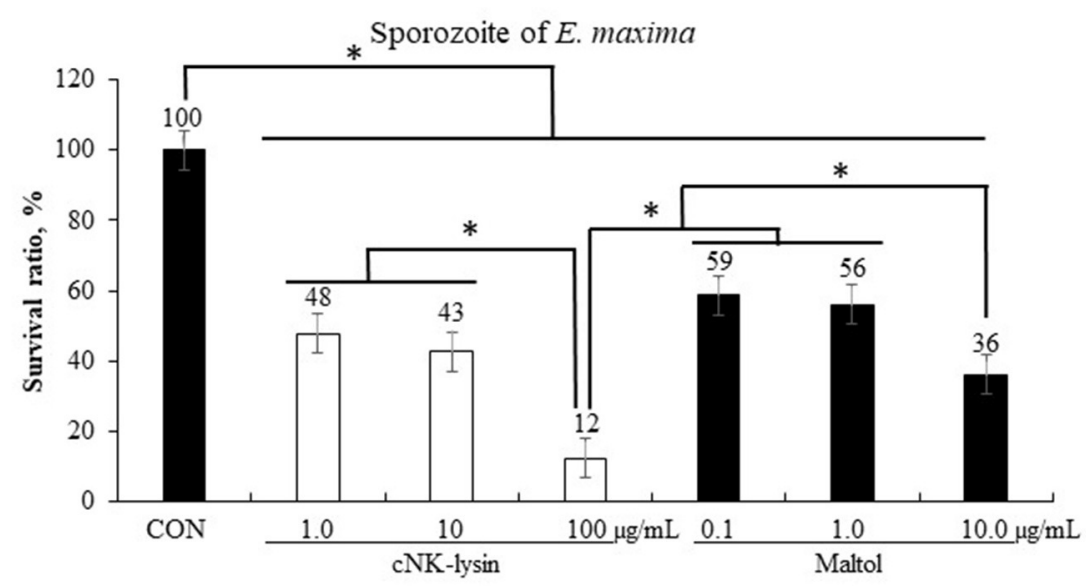

FIGURE 5 | Anticoccidial effect of maltol on sporozoites of E. maxima in experiment 1. Each bar represents the mean \pm SEM $(n=3)$. Significant results are marked as ${ }^{*}(P<0.05)$. CON, $2.5 \times 10^{5}$ sporozoites $/ \mathrm{mL}$.

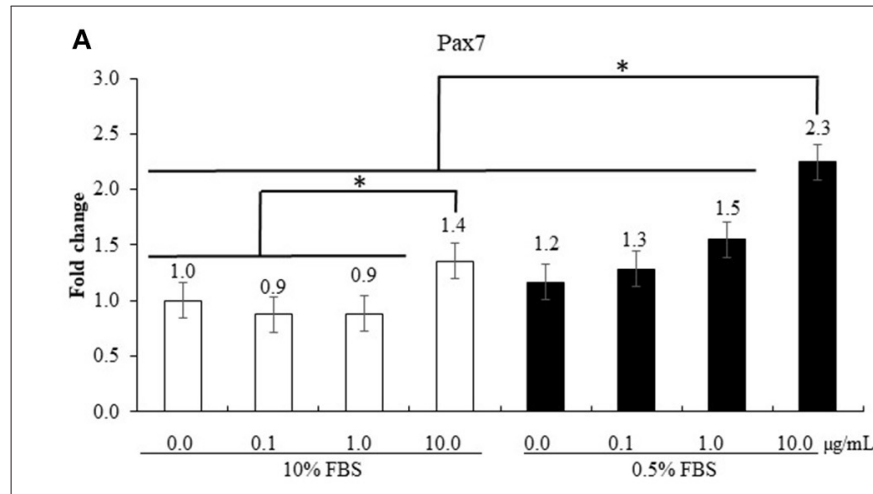

C

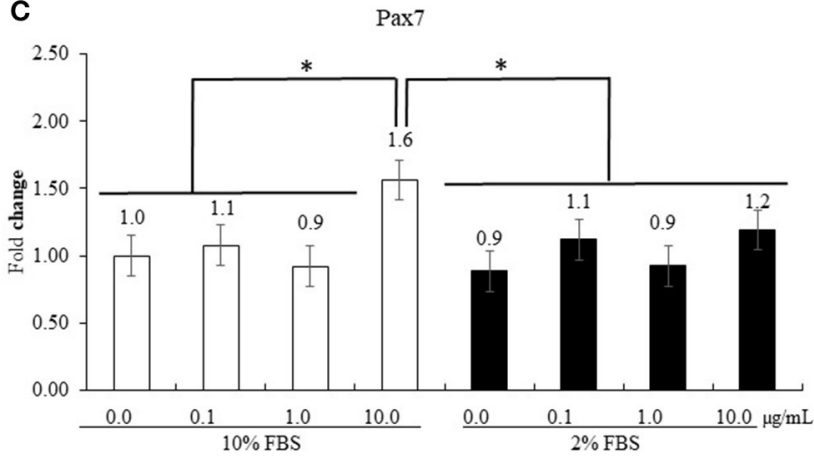

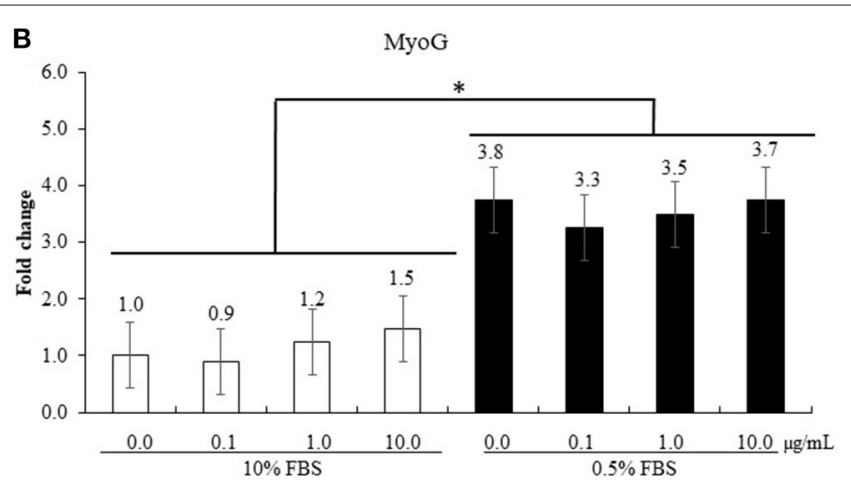

D

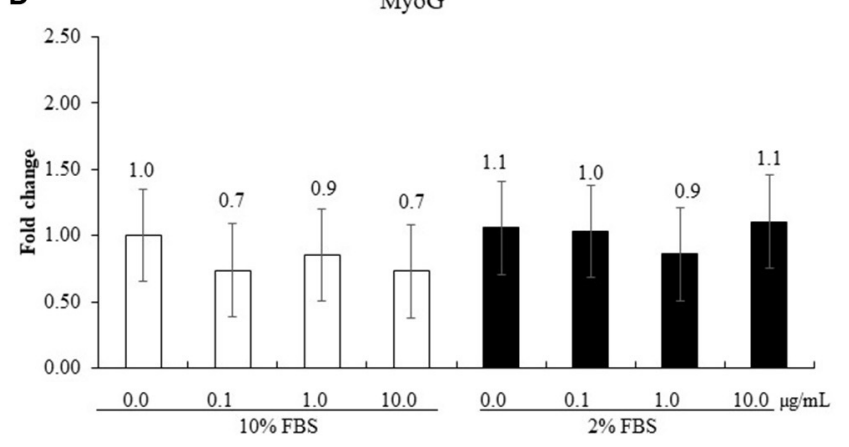

FIGURE 6 | Proliferation and differentiation of quail muscle cells [QMC, $(\mathbf{A}, \mathbf{B})]$ and primary chicken embryonic muscle cells $[\mathrm{PMC},(\mathbf{C}, \mathbf{D})]$ by FBS concentration and maltol. Each bar represents the mean \pm SEM $(n=3)$. Transcript levels of the cytokines were measured using quantitative RT-PCR and normalized to GAPDH transcript levels. Significant results are marked as follows: ${ }^{*}(P<0.05)$.

(Figure 7A). The HI group decreased $(P=0.024)$ the lesion score of the jejunum (1.5-1.2) compared to that of the NC group. In the NC group, infection increased $(P<0.001)$ the oocyst numbers $\left(0-5.6 \times 10^{7}\right.$ oocysts/chicken) compared to that of the CON group; however, the HI group decreased $(P=0.002)$ the fecal oocyst number $\left(5.6 \times 10^{7}-3.8 \times 10^{7}\right.$ oocysts/chicken $)$ compared to that of the NC group (Figure 7B).

\section{Pro-inflammatory Cytokines}

In the absence of maltol, infection (NC group) with E. maxima increased $(P<0.05)$ the gene expression of TNFSF15 $(3.4 \times$ $\left.10^{-3}-2.3 \times 10^{-2}\right)$, IL- $1 \beta\left(1.9 \times 10^{-3}-4.9 \times 10^{-3}\right)$, and IL-6 $(3.0 \times$ $\left.10^{-3}-9.9 \times 10^{-3}\right)$ in the distal jejunum compared to that of the CON group (Figure 8). The HI group decreased $(P<0.05)$ the expression of TNFSF15 $\left(2.3 \times 10^{-2}-8.2 \times 10^{-3}\right)$, IL-1 $\beta(4.9 \times$ 
TABLE 3 | Body weight and average daily gain chickens fed a diet supplemented with maltol.

\begin{tabular}{|c|c|c|c|c|c|c|}
\hline Treatment & CON & NC & HI & LO & SEM & $P$-value \\
\hline \multicolumn{7}{|l|}{ BW, g } \\
\hline Initial & 36.6 & 36.6 & 36.6 & 36.6 & 0.7 & 0.998 \\
\hline D 7 & 157 & 159 & 161 & 162 & 2.7 & 0.651 \\
\hline D 14 (0 dpi) & 461 & 457 & 472 & 473 & 8.8 & 0.509 \\
\hline D 20 (6 dpi) & $860^{a}$ & $743^{c}$ & $794^{b}$ & $724^{c}$ & 17 & $<0.001$ \\
\hline D 22 (8 dpi) & $1,017^{a}$ & $763^{d}$ & $934^{b}$ & $842^{c}$ & 22 & $<0.001$ \\
\hline \multicolumn{7}{|l|}{ ADG, $\mathbf{g}$} \\
\hline D 0 to 7 & 20.0 & 20.4 & 21.0 & 20.8 & 0.3 & 0.169 \\
\hline D 7 to 14 & 43.5 & 41.9 & 44.4 & 44.6 & 1.0 & 0.214 \\
\hline D 0 to $14^{1}$ & 32.7 & 32.2 & 33.3 & 33.6 & 0.6 & 0.434 \\
\hline D 14 to 20 & $66.5^{\mathrm{a}}$ & $47.7^{\mathrm{c}}$ & $53.7^{b}$ & $41.9^{d}$ & 1.6 & $<0.001$ \\
\hline D 14 to $22^{2}$ & $69.4^{a}$ & $38.2^{d}$ & $57.8^{b}$ & $46.9^{c}$ & 1.9 & $<0.001$ \\
\hline
\end{tabular}

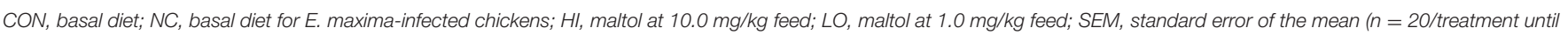
day 20 and 16/treatment at day 22).

${ }^{1}$ Before infection.

${ }^{2}$ After infection.

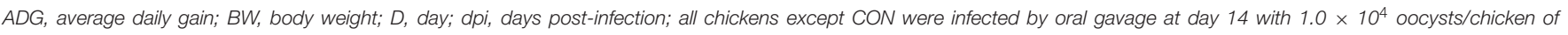
E. maxima.

${ }^{a-d}$ Means in the same row with different superscripts differ $(P<0.05)$ and the difference was re-evaluated by PDIFF option in SAS when $P$-value between treatments was <0.05.

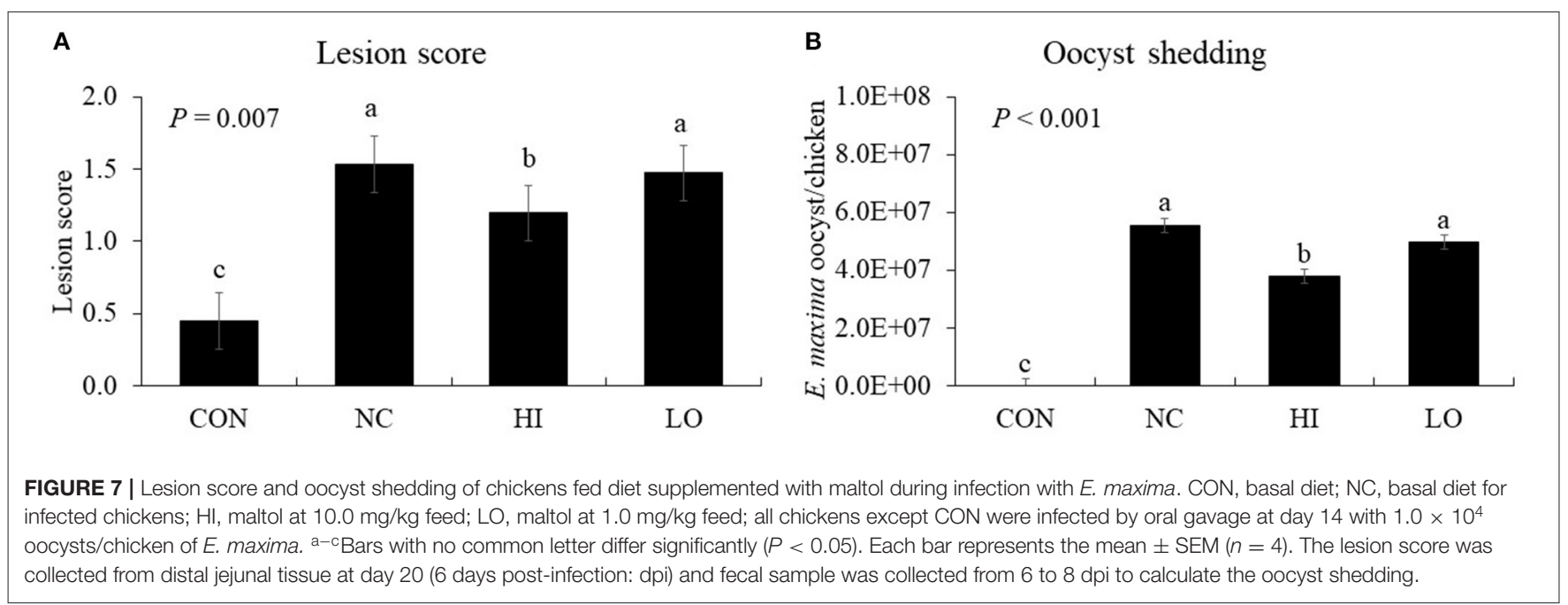

$\left.10^{-3}-1.6 \times 10^{-3}\right)$, IL-6 $\left(9.9 \times 10^{-3}-4.4 \times 10^{-3}\right)$, and IL-17F $\left(1.0 \times 10^{-3}-5.0 \times 10^{-5}\right)$ compared to that of the NC group. The LO group also decreased $(P<0.05)$ the gene expression of IL$6\left(9.9 \times 10^{-3}-4.7 \times 10^{-3}\right)$ and IL-17F $\left(1.0 \times 10^{-3}-6.0 \times 10^{-5}\right)$ compared to that of the NC group.

\section{Th1 Cytokines}

In the absence of maltol, challenge infection (NC group) with $E$. maxima increased $(P<0.05)$ the gene expression of IFN- $\gamma(5.1$ $\left.\times 10^{-5}-2.5 \times 10^{-3}\right)$ and IL-10 $\left(9.1 \times 10^{-5}-1.2 \times 10^{-3}\right)$ in the distal jejunum compared to that of the CON group (Figure 9). However, the HI and LO groups decreased $(P<0.05)$ the gene expression of IFN- $\gamma$ (HI: $2.5 \times 10^{-3}-4.1 \times 10^{-4}$, and LO: 2.5 $\times 10^{-3}-4.6 \times 10^{-4}$ ) and IL-10 (HI: $1.2 \times 10^{-3}-2.4 \times 10^{-4}$ and LO: $1.2 \times 10^{-3}-3.5 \times 10^{-4}$ ) compared to their respective NC controls.

\section{TJ Proteins}

In the absence of maltol, challenge infection (NC group) with $E$. maxima decreased $(P=0.033)$ the gene expression of occludin $\left(1.4 \times 10^{-2}-8.8 \times 10^{-3}\right)$ in the distal jejunum compared to that in the CON group (Figure 10). However, the $\mathrm{HI}\left(8.8 \times 10^{-3}-1.9 \times 10^{-2}\right)$ and $\mathrm{LO}\left(8.8 \times 10^{-3}\right.$. $\left.1.4 \times 10^{-2}\right)$ groups increased $(P<0.031)$ occludin gene expression compared to that of the NC group. Other TJ proteins such as claudin-1, JAM2, and ZO-1 did not demonstrate any significant changes in gene expression $(P>0.05)$ following maltol treatment. 


\section{A}

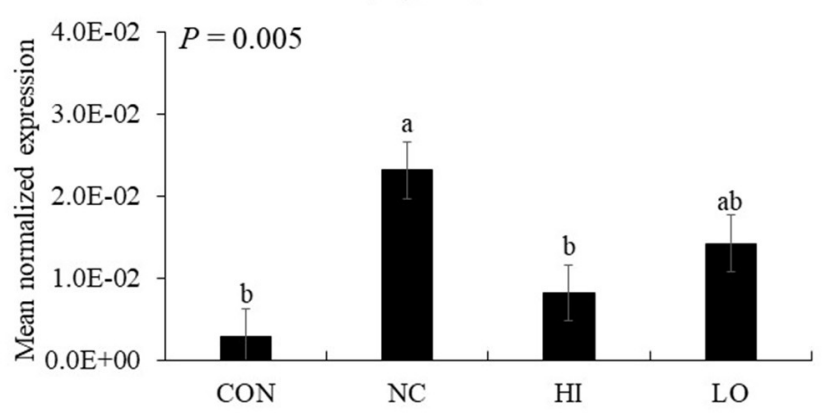

C

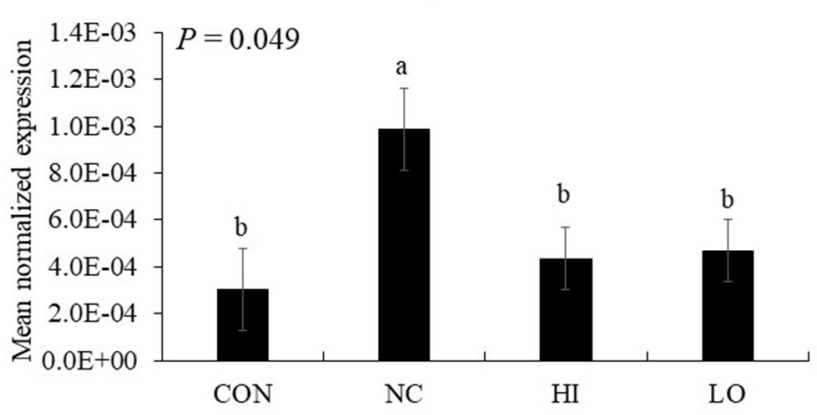

B

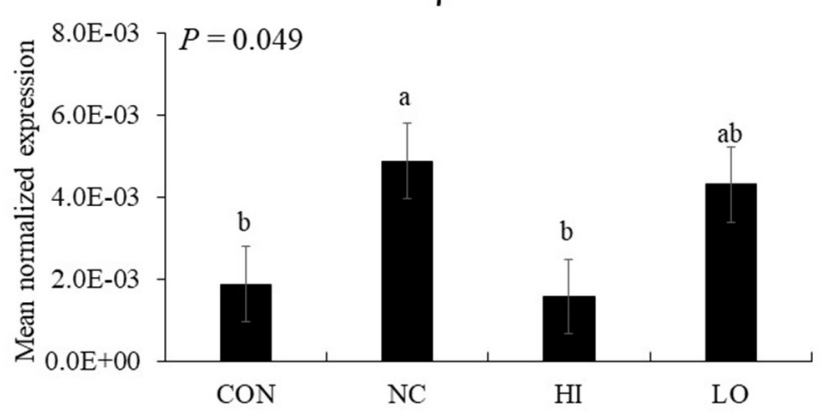

D

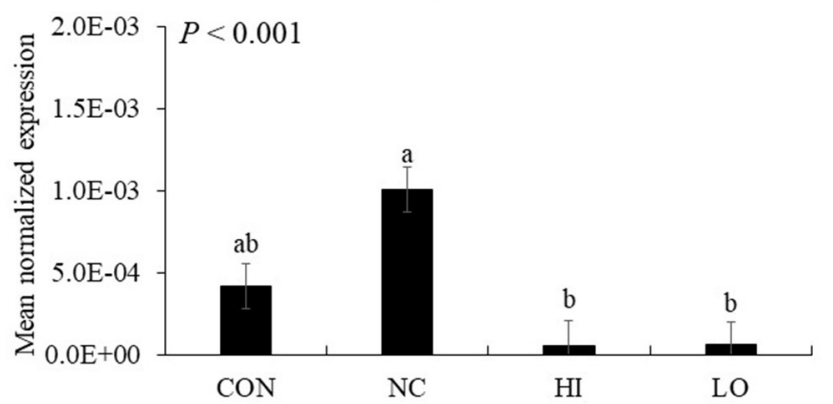

FIGURE 8 | Transcripts of proinflammatory cytokines in jejunum of chickens fed diet supplemented with maltol during infection with E. maxima in experiment 2. CON, basal diet; NC, basal diet for infected chickens; HI, maltol at $10.0 \mathrm{mg} / \mathrm{kg}$ feed; LO, maltol at $1.0 \mathrm{mg} / \mathrm{kg}$ feed; all chickens except CON were infected by oral gavage at day 14 with $1.0 \times 10^{4}$ oocysts/chicken of $E$. maxima. ${ }^{a, b}$ Bars with no common letter differ significantly $(P<0.05)$. Each bar represents the mean \pm SEM $(n=4)$. The data were collected at day 20 (6 days post-infection). Transcript levels of the cytokines were measured using quantitative RT-PCR and normalized to GAPDH transcript levels.

\section{A}

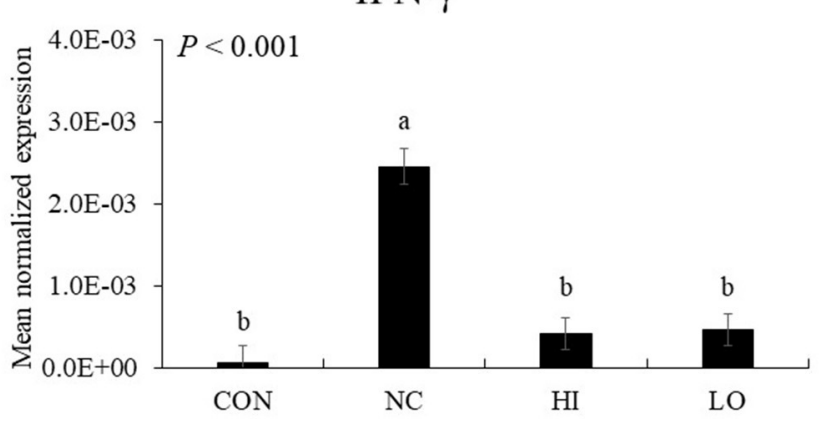

B

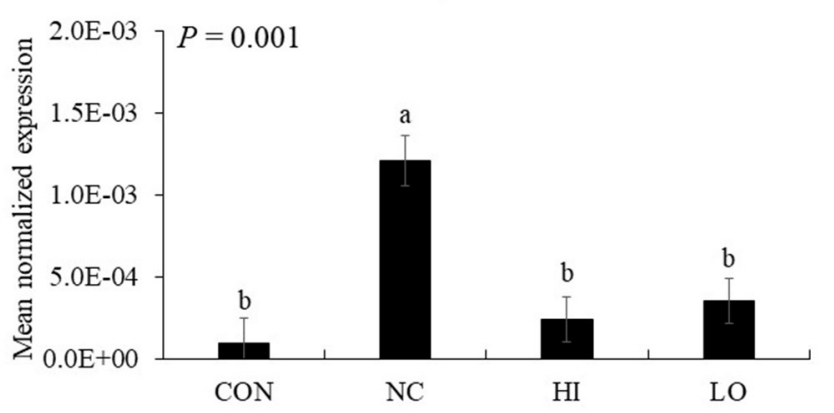

FIGURE 9 | Transcripts of Th1 cytokines in jejunum of chickens fed diet supplemented with maltol during infection with E. maxima in experiment 2. CON, basal diet; $\mathrm{NC}$, basal diet for infected chickens; HI, maltol at $10.0 \mathrm{mg} / \mathrm{kg}$ feed; LO, maltol at $1.0 \mathrm{mg} / \mathrm{kg}$ feed; all chickens except CON were infected by oral gavage at day 14 with $1.0 \times 10^{4}$ oocysts/chicken of $E$. maxima. ${ }^{a},{ }^{b}$ Bars with no common letter differ significantly $(P<0.05)$. Each bar represents the mean $\pm \mathrm{SEM}(n=4)$. The data were collected at day 20 (6 days post-infection). Transcript levels of the cytokines were measured using quantitative RT-PCR and normalized to GAPDH transcript levels.

\section{DISCUSSION}

Analysis of metabolites produced by gut microbiota-mediated metabolism of indigestible feed ingredients has provided evidence of profound effects of small molecular weight metabolites on the signal transduction of the host and as regulators of host physiological responses $(18,31,32)$. Recently, several metabolites have been named as postbiotics, which are defined as types of feed additives that are generally produced by beneficial gut microbes and exert a positive effect on host health (18). For example, short-chain fatty acids, bacteriocins, functional peptides, and proteins are known as postbiotics (33, $34)$; therefore, gut metabolites are considered as postbiotics. In our previous study (19), we performed a global metabolomic 

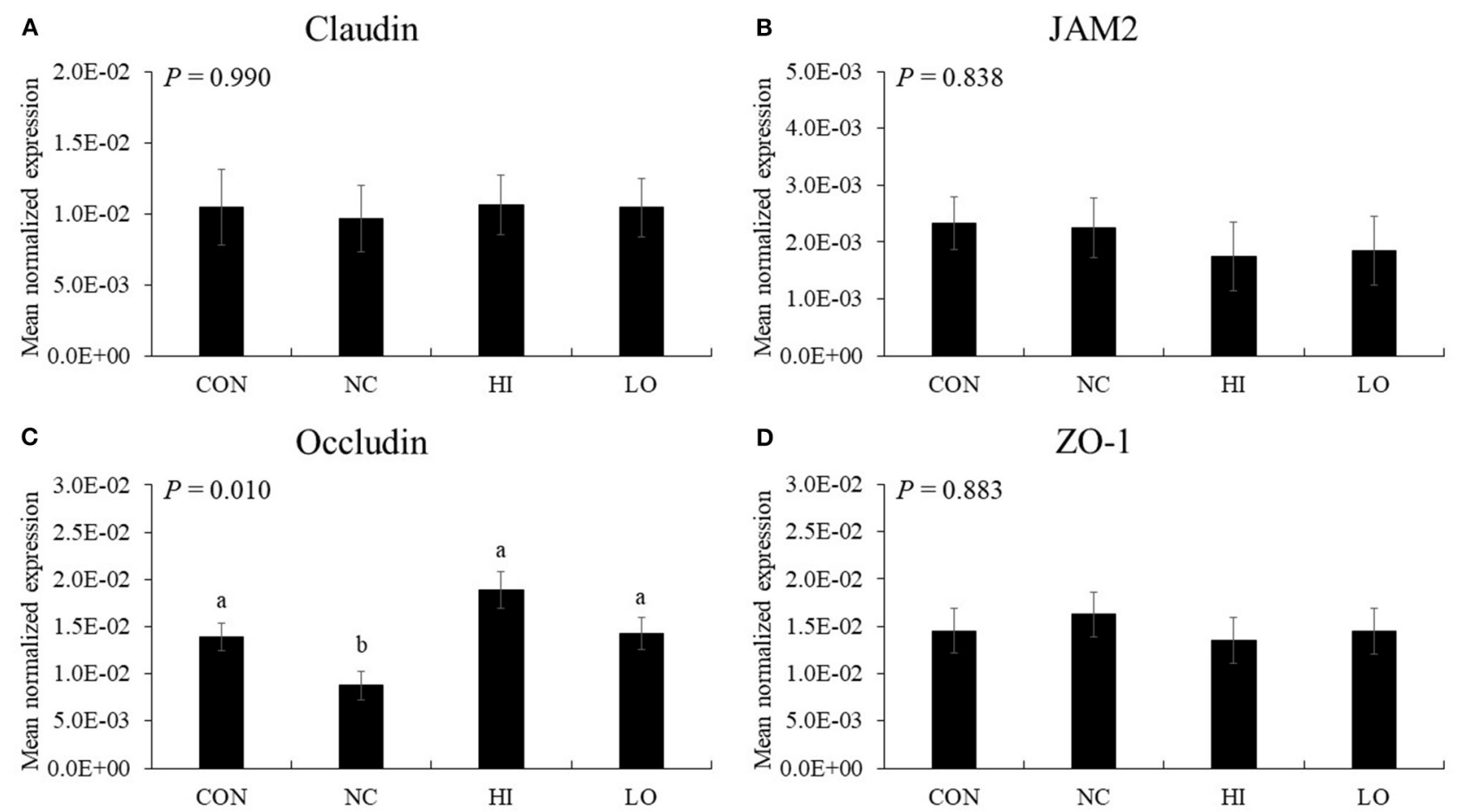

FIGURE 10 | Transcripts of tight junction protein in jejunum of chickens fed diet supplemented with maltol during infection with E. maxima in experiment 2. CON, basal diet; NC, basal diet for infected chickens; HI, maltol at $10.0 \mathrm{mg} / \mathrm{kg}$ feed; LO, maltol at $1.0 \mathrm{mg} / \mathrm{kg}$ feed; all chickens except CON were infected by oral gavage at day 14 with $1.0 \times 10^{4}$ oocysts/chicken of $E$. maxima. ${ }^{a, b}$ Bars with no common letter differ significantly $(P<0.05)$. Each bar represents the mean \pm SEM $(n=4)$. The data were collected at day 20 (6 days post-infection). Transcript levels of the tight junction proteins were measured using quantitative RT-PCR and normalized to GAPDH transcript levels.

analysis of gut metabolites associated with growth and immunity enhancement following dietary exposure of young chickens with direct-fed microbes, B. subtilis 1781 and 747, which promote growth and immunity. Of the 361 metabolites that were altered in chickens treated with $B$. subtilis 1781 and 747, 131 metabolites were increased and 230 metabolites were decreased compared to the non-supplemented control group. Maltol was identified as one of the markedly increased metabolites with potentially beneficial effects on gut health and chicken growth.

In experiment 1 , the effects of maltol on the gene expression of pro-inflammatory cytokines in IEC and CMC, TJ proteins in IEC, and anticoccidial ability against sporozoite of E. maxima, were evaluated in vitro. LPS was used to induce inflammatory responses in IEC and $\mathrm{CMC}$, and its treatment elevated levels of all pro-inflammatory cytokines tested. The magnitude of cytokine gene expression was greater in $\mathrm{CMC}$ than that in IEC. In IEC, IL-1 $\beta$ and IL-6 levels were increased by 1.4 and 2.3 times, respectively, compared to those in each control without LPS treatment, whereas in CMC, IL-1 $\beta$, IL-6, and IL8 levels were increased by $9.1,4.2$, and 7.7 times, respectively, compared to their respective controls. Therefore, CMC was more responsive to the LPS treatment than to the IEC treatment, and the findings were supported by a previous study which showed that macrophages were more sensitive to LPS-induced immune responses than epithelial cells (35). LPS treatment of
IEC and CEC in the present study increased expression levels of all cytokines analyzed, and maltol, at doses from $0.1 \mu \mathrm{g} / \mathrm{mL}$ (1.6-fold higher than the LPS control) to $1.0 \mu \mathrm{g} / \mathrm{mL}(2.5$-fold higher than the LPS control), induced IL- 6 levels of IEC in a dose-dependent manner. However, maltol at a dose of $10 \mu \mathrm{g} / \mathrm{mL}$ maintained the same level of IL- 6 expression as that observed at doses of 0.1 and $1.0 \mu \mathrm{g} / \mathrm{mL}$. For CMC, regardless of the dose administered, maltol induced higher IL- $1 \beta$ and IL- 8 levels compared to those of the LPS control without maltol addition. IL-6 showed the most remarkable change at the lowest maltol concentration $(0.1 \mu \mathrm{g} / \mathrm{mL})$ among the LPS-treated groups. Other maltol concentrations $(1.0$ and $10.0 \mu \mathrm{g} / \mathrm{mL})$ did not affect the LPS-induced IL-6 levels.

Our in vitro studies showed that maltol played a role as an immune modulator during inflammatory responses. Maltol also influences the anti-oxidant activity (22) by scavenging free radicals generated during oxidative stress (20). Oxidative stress incurred during an inflammatory response may trigger the overproduction of reactive oxygen species, which can form a vicious circle resulting in tissue damage in intestinal epithelia and liver tissues (36). Maltol treatment has shown effective protection of nerve cells against oxidative damage caused by reactive oxygen species (33), and maltol-derived organometallic complexes have also been shown to demonstrate potential antitumor activity (21). Pro-inflammatory cytokines are involved in 
mucosal inflammation, disruption of the physiological epithelial TJ structure and composition, and can increase paracellular permeability (37). However, the molecular mechanisms that drive TJ reorganization in such inflammatory states are not wellunderstood. Only maltol in the absence of LPS upregulated the gene expression of occludin, ZO-1, and MUC2 levels in IEC by more than 2-fold, regardless of the dose administered compared to the control. Based on our observations, maltol may exert a beneficial effect on maintenance of gut integrity and improve the gene expression of TJ proteins. Further studies are warranted to clarify the role of maltol and TJ proteins in IEC.

Maltol also reduced the survival ratio of sporozoites of E. maxima, although the underlying reason for this needs further investigation. A previous study showed that 1-(N-acetyl-6aminohexyl)-3-hydroxy-2-methylpyridib-one, synthesized from maltol, inhibited the growth of Plasmodium falciparum by interfering with the uptake of exogenous iron or by depleting the intracellular labile iron pool (38). Since both Eimeria and Plasmodia belong to the Apicomplexa phylum, maltol may use a similar mechanism to inhibit the growth of these protozoan parasites. The observed effects of maltol on muscle cells in vitro warrant further study. In the present study, we used different FBS concentrations [0.5\% FBS in QMC (39) and 2\% FBS in PMC (40)] to induce myogenic differentiation and proliferation. During myoblast proliferation, maltol administration at a dose of $10 \mu \mathrm{g} / \mathrm{mL}$ enhanced Pax7 levels in QMCs and PMCs. However, regardless of the dose administered, maltol treatment did not affect the MyoG levels of QMCs and PMCs during myogenic differentiation. Maltol at a dose of $10 \mu \mathrm{g} / \mathrm{mL}$ also increased Pax7 levels in QMCs during myogenic differentiation. Choi et al. (41) reported that high levels of Pax7 could impair myogenesis formation. According to our observation, QMCs and PMCs present with different cell growth properties because PMCs are undifferentiated primary cells obtained from chicken embryos, whereas QMCs are established muscle cells obtained from quails.

To further study the role of maltol in chickens, we conducted an in vivo feeding trial in young broiler chickens infected with E. maxima. Specifically, the effects of dietary maltol at high and low doses on growth performance, intestinal immune responses, and epithelial barrier integrity of chickens following challenge infection with E. maxima were examined. Regardless of the dose administered, dietary maltol supplementation in young chickens did not affect the BW and ADG before E. maxima infection. Therefore, dietary maltol supplementation in broiler chicken may not influence the growth of chickens by itself. However, in the present study, dietary maltol supplementation up to $10 \mu \mathrm{g} / \mathrm{kg}$ feed did not adversely affect the growth performance of young broiler chickens. After infection with E. maxima, dietary maltol supplementation showed various changes in the physiological responses of broiler chickens. Following E. maxima infection, the growth performance (BW and ADG) of the broiler chickens were decreased compared to that of the CON group regardless of the dietary maltol supplemented. However, at $6 \mathrm{dpi}$, the BW of chickens were improved when chickens were provided with dietary HI maltol levels of $10.0 \mu \mathrm{g} / \mathrm{kg}$, and the effects could be observed until the end of the experiment. When chickens were provided with LO maltol levels of $1.0 \mu \mathrm{g} / \mathrm{kg}$ feed, BW showed improvement only at $8 \mathrm{dpi}$. The effect of dietary maltol supplementation on BW was also investigated to determine changes in the ADG of chickens, with the HI group showing improvements in the ADG between 0 and $8 \mathrm{dpi}$ (the entire infection duration). These results indicate the beneficial effects of dietary maltol on the BW and ADG of chickens following E. maxima infection. The beneficial effect of maltol on muscle growth is an important finding which suggests a potential use of maltol as an alternative to antibiotics. Therefore, further studies are needed to investigate the mechanisms of growth promotion by maltol since the focus of current study was to show the effect of dietary maltol on gut function including local immunity in broiler chickens.

The results of our in vitro and in vivo experiments supported our hypothesis that dietary maltol supplementation could improve the growth of broiler chickens infected with E. maxima and indicated that maltol was a good candidate as a postbiotic antibiotic alternative. To further investigate the effect of dietary maltol on the growth performance of chickens, we determined jejunal lesion score, gene expression of jejunal cytokines and TJ proteins, and fecal oocyst shedding in broiler chickens infected with E. maxima. Dietary maltol supplementation decreased the jejunal lesion score and fecal oocyst production, indicating a potential direct role of dietary maltol on Eimeria fecundity or host cell invasion at the brush border of the intestine. This result was supported by our in vitro results showing the direct action of maltol on the survival of sporozoites of E. maxima in the present study. Another explanation for the decrease in gut lesions and fecal oocyst shedding could be provided by the effects of maltol treatment on cytokine and TJ protein expression in the gut. Expression levels of the cytokines, which are mostly involved in the elicitation of pro-inflammatory and Th1 responses, increased after challenge infection with E. maxima. However, following E. maxima infection, dietary maltol supplementation suppressed the gene expression levels of IL-6, IL-17F, IFN- $\gamma$, and IL-10 compared to those of the NC group. These results suggest a role played by dietary maltol in induction of host immune responses and oocyst reduction during E. maxima infection.

Klasing (42) has reported that a cytokine storm induces metabolic changes, including increased protein degradation in skeletal muscle, thereby diverting nutrients from the muscle and other tissues to render their availability for the increased demands of leukocytes and production of protective proteins. Consequently, these responses decrease growth performance and directly influence the success of poultry production. In practice, under equalized feed intake, a vigorous acute phase immune response in chickens has been estimated to account for approximately $10 \%$ of the nutrient use (42). Jiang et al. (43) reported that LPS-challenged chickens (dose of $1 \mathrm{mg}$ LPS per $\mathrm{kg}$ of BW at 14, 16, 18, and 20 days of age) showed a $22 \%$ decrease in BW gain during challenge; $59 \%$ of the loss was attributed to a decreased feed intake, and the remaining $41 \%$ was attributed to the presence of immune response-related factors (44). Park et al. (3) suggested that cytokines that reduced pro-inflammatory and cellular immune responses could decrease the turnover of feed nutrients utilized for immune protein production, which might lead to exertion of growth-promoting effects on chickens. 
This concept is also supported by studies and reviews related to nutrition and immunity in poultry (43-45). The intestinal epithelium, composed of a single layer of columnar epithelial cells that are tightly bound by intercellular junctional complexes, serves as a physical barrier against invading pathogens and intraluminal toxins $(46,47)$. Intestinal junctional complexes maintain the integrity of the epithelial barrier by regulating paracellular permeability and are composed of TJs, gap junctions, adherens junctions, and desmosomes (48). TJs include four integral transmembrane proteins (occludin, claudin-1, JAM, and tricellulin) that interact with cytosolic scaffold proteins, which bind the actin cytoskeleton $(46,49)$. Jejunal TJ proteins levels, except those for occludin, were not affected by E. maxima infection or dietary maltol supplementation in the present study. However, occludin levels were decreased by E. maxima infection, and the reduction was recovered by dietary maltol supplementation in a dose-dependent manner. Our results were supported by findings reported by Van Itallie et al. (50), who stated that occludin was required for cytokine-induced TJ remodeling, however, dietary maltol did not affect other TJ proteins unlike our in vitro results. Thus, further studies on the effects of maltol on TJ proteins will enhance our understanding of maltol-gut junction protein interaction.

In conclusion, maltol, one of the metabolites whose expression was increased in the gut of young broiler chickens fed with a diet supplemented with B. subtilis 1781 and 747, that promotes host immunity and growth, affected the maintenance of gut integrity and the functions of immunity in vitro and exerted beneficial effects by reducing intestinal damage, parasite fecundity, and

\section{REFERENCES}

1. Shirley MW, Lillehoj HS. The long view : a selective review of 40 years of coccidiosis research. Avian Pathol. (2017) 41:37-41. doi: 10.1080/03079457.2012.666338

2. Cunha AF da, Santin E, Kogut M. Editorial: poultry coccidiosis: strategies to understand and control. Front Vet Sci. (2020) 7:1-2. doi: 10.3389/fvets.2020.599322

3. Park I, Lee Y, Goo D, Zimmerman NP, Smith AH, Rehberger T, et al. The effects of dietary Bacillus subtilis supplementation, as an alternative to antibiotics, on growth performance, intestinal immunity, and epithelial barrier integrity in broiler chickens infected with Eimeria maxima. Poult Sci. (2020) 99:725-33. doi: 10.1016/j.psj.2019.12.002

4. Peek HW, Landman WJM. Coccidiosis in poultry: anticoccidial products, vaccines and other prevention strategies. Vet Q. (2011) 31:143-61. doi: 10.1080/01652176.2011.605247

5. Lillehoj H, Liu Y, Calsamiglia S, Fernandez-Miyakawa ME, Chi F, Cravens RL, et al. Phytochemicals as antibiotic alternatives to promote growth and enhance host health. Vet Res. (2018) 49:1-18. doi: 10.1186/s13567-018-0562-6

6. Landers TF, Cohen B, Wittum TE, Larson EL. A review of antibiotic use in food animals: perspective, policy, and potential. Public Health Rep. (2012) 127:4-22. doi: 10.1177/003335491212700103

7. Gadde U, Kim WH, Oh ST, Lillehoj HS. Alternatives to antibiotics for maximizing growth performance and feed efficiency in poultry: a review. Anim Heal Res Rev. (2017) 18:26-45. doi: 10.1017/S1466252316000207

8. Choi KY, Lee TK, Sul WJ. Metagenomic analysis of chicken gut microbiota for improving metabolism and health of chickens - a review. Asian Aust J Anim Sci. (2015) 28:1217-25. doi: 10.5713/ajas.15.0026

9. Rampelli S, Soverini M, D’Amico F, Barone M, Tavella T, Monti D, et al. Shotgun metagenomics of human gut microbiota up to extreme longevity and inflammatory responses in chickens following E. maxima challenge infection. Therefore, maltol is a good candidate as an antibiotic alternative postbiotic to improve the growth and immunity of chickens presenting with enteric diseases.

\section{DATA AVAILABILITY STATEMENT}

The original contributions presented in the study are included in the article/supplementary material, further inquiries can be directed to the corresponding author/s.

\section{ETHICS STATEMENT}

The animal study was reviewed and approved by the Beltsville Agricultural Research Center Small Animal Care Committee (Animal Protocol No. 19-018).

\section{AUTHOR CONTRIBUTIONS}

IP and HL designed the research and draft the manuscript and edit. IP and SW conducted the research. IP, DG, HN, SW, and KL analyzed data. IP, DG, HN, SW, KL, NZ, AS, TR, and HL had responsibility for content. All authors contributed to the article and approved the submitted version.

\section{FUNDING}

Funding was partly supported by ARS CRIS 8042-32000-107-00D. the increasing role of xenobiotics degradation. mSystems. (2020) 5:e0012420. doi: $10.1128 / \mathrm{mSystems.00124-20}$

10. Ji B, Nielsen J. From next-generation sequencing to systematic modeling of the gut microbiome. Front Genet. (2015) 6:1-9. doi: 10.3389/fgene.2015.00219

11. Malla MA, Dubey A, Kumar A, Yadav S, Hashem A, Allah EFA. Exploring the human microbiome: the potential future role of next-generation sequencing in disease diagnosis and treatment. Front Immunol. (2019) 10:123. doi: 10.3389/fimmu.2018.02868

12. Waldor MK, Tyson G, Borenstein E, Ochman H, Moeller A, Finlay BB, et al. Where next for microbiome research? PLoS Biol. (2015) 13:19. doi: 10.1371/journal.pbio.1002050

13. Rezasoltani S, Bashirzadeh DA, Mojarad EN, Aghdaei HA, Norouzinia M, Shahrokh S. Signature of gut microbiome by conventional and advanced analysis techniques: advantages and disadvantages. Middle East J Dig Dis. (2020) 12:249-55. doi: 10.15171/mejdd.2020.157

14. Aguiar-pulido V, Huang W, Suarez-ulloa V, Cickovski T, Mathee K, Narasimhan G. Metagenomics, metatranscriptomics, and metabolomics approaches for microbiome analysis. Evol Bioinform Online. (2016) 12:516. doi: 10.4137/EBO.S36436

15. Bashiardes S, Zilberman-schapira G, Elinav E. Bashiardes, use of metatranscriptomics in microbiome research. Bioinform Biol Insights. (2016) 10:19-25. doi: 10.4137/BBI.S34610

16. Hornung B, Martins dos Santos VAP, Smidt H, Schaap PJ. Studying microbial functionality within the gut ecosystem by systems biology. Genes Nutr. (2018) 13:1-19. doi: 10.1186/s12263-018-0594-6

17. Wang Y, Zhou Y, Xiao X, Zheng J, Zhou H. Metaproteomics: a strategy to study the taxonomy and functionality of the gut microbiota. J Proteomics. (2020) 219:103737. doi: 10.1016/j.jprot.2020.103737

18. Johnson $\mathrm{CN}$, Kogut $\mathrm{MH}$, Genovese $\mathrm{K}$, He H, Kazemi S, Arsenault RJ. Administration of a postbiotic causes immunomodulatory responses 
in broiler gut and reduces disease pathogenesis following challenge. Microorganisms. (2019) 7:268. doi: 10.3390/microorganisms7080268

19. Park I, Zimmerman NP, Smith AH, Rehberger TG, Lillehoj EP, Lillehoj HS. Dietary supplementation with Bacillus subtilis direct-fed microbials alters chicken intestinal metabolite levels. Front Vet Sci. (2020) 7:19. doi: 10.3389/fvets.2020.00123

20. Han Y, Xu Q, Hu JN, Han XY, Li W, Zhao LC. Maltol, a food flavoring agent, attenuates acute alcohol-induced oxidative damage in mice. Nutrients. (2015) 20:682-96. doi: 10.3390/nu7010682

21. Dömötör O, Aicher S, Schmidlehner M, Novak MS, Roller A, Jakupec MA, et al. Antitumor pentamethylcyclopentadienyl rhodium complexes of maltol and allomaltol: synthesis, solution speciation and bioactivity. J Inorg Biochem. (2014) 134:57-65. doi: 10.1016/j.jinorgbio.2014.01.020

22. Wang Z, Hao W, Hu J, Mi X, Han Y, Ren S, et al. Maltol improves APAP-induced hepatotoxicity by inhibiting oxidative stress and inflammation response via NF-kb and pi3k/akt signal pathways. Antioxidants. (2019) 8:395. doi: 10.3390/antiox8090395

23. Lee SH, Lillehoj HS, Jang SI, Lee KW, Baldwin C, Tompkins D, et al. Development and characterization of mouse monoclonal antibodies reactive with chicken CD83. Vet Immunol Immunopathol. (2012) 145:52733. doi: $10.1016 /$ j.vetimm.2011.11.020

24. Kim WH, Lillehoj HS, Min W. Evaluation of the immunomodulatory activity of the chicken NK-lysin-derived peptide cNK-2. Sci Rep. (2017) 7:1-11. doi: 10.1038/srep45099

25. Hassan A, Ahn J, Suh Y, Choi YM, Chen P, Lee K. Selenium promotes adipogenic determination and differentiation of chicken embryonic fibroblasts with regulation of genes involved in fatty acid uptake, triacylglycerol synthesis and lipolysis. J Nutr Biochem. (2014) 25:858-67. doi: 10.1016/j.jnutbio.2014.03.018

26. Muller PY, Janovjak H, Miserez AR, Dobbie Z. Processing of gene expression data generated by quantitative real-time RT-PCR. Biotechniques. (2002) 32:1372-4.

27. Lillehoj HS, Lee SH, Park SS, Jeong M, Lim Y, Mathis GF, et al. Calcium montmorillonite-based dietary supplement attenuates necrotic enteritis induced by Eimeria maxima and Clostridium perfringens in broilers. J Poult Sci. (2016) 53:329-40. doi: 10.2141/jpsa.0150182

28. Haug A, Thebo P, Mattsson JG. A simplified protocol for molecular identification of Eimeria species in field samples. Vet Parasitol. (2007) 146:3545. doi: 10.1016/j.vetpar.2006.12.015

29. Johnson J, Reid WM. Anticoccidial drugs: lesion scoring techniques in battery and floor-pen experiments with chickens. Exp Parasitol. (1970) 28:306. doi: 10.1016/0014-4894(70)90063-9

30. Lee KW, Li G, Lillehoj HS, Lee SH, Jang SI, Babu US, et al. Bacillus subtilisbased direct-fed microbials augment macrophage function in broiler chickens. Res Vet Sci. (2011) 91:87-91. doi: 10.1016/j.rvsc.2011.01.018

31. Lee WJ, Hase K. Gut microbiota-generated metabolites in animal health and disease. Nat Chem Biol. (2014) 10:416-24. doi: 10.1038/nchembio. 1535

32. Blacher E, Levy M, Tatirovsky E, Elinav E. Microbiome-modulated metabolites at the interface of host immunity. J Immunol. (2017) 198:57280. doi: 10.4049/jimmunol.1601247

33. Klemashevich C, Wu C, Howsmon D, Alaniz RC, Lee K, Jayaraman A. Rational identification of diet-derived postbiotics for improving intestinal microbiota function. Curr Opin Biotechnol. (2014) 26:85-90. doi: 10.1016/j.copbio.2013.10.006

34. Cicenia A, Scirocco A, Carabotti M, Pallotta L, Marignani M, Severi C. Postbiotic activities of lactobacilli-derived factors. J Clin Gastroenterol. (2014) 48:S18-22. doi: 10.1097/MCG.0000000000000231

35. Mubarak R Al, Roberts N, Mason RJ, Alper S, Chu HW. Comparison of pro- and anti-inflammatory responses in paired human primary airway epithelial cells and alveolar macrophages. Respir Res. (2018) 19:114. doi: 10.1186/s12931-018-0825-9

36. Mittal M, Siddiqui MR, Tran K, Reddy SP, Malik AB. Reactive oxygen species in inflammation and tissue injury. Antioxidants Redox Signal. (2014) 20:1126-67. doi: 10.1089/ars.2012.5149
37. Capaldo CT, Farkas AE, Hilgarth RS, Krug SM, Wolf MF, Benedik JK, et al. Proinflammatory cytokine-induced tight junction remodeling through dynamic self-assembly of claudins. Mol Biol Cell. (2014) 25:27109. doi: 10.1091/mbc.e14-02-0773

38. Thipubon P, Uthaipibull C, Kamchonwongpaisan S, Tipsuwan W, Srichairatanakool S. Inhibitory effect of novel iron chelator, 1-(Nacetyl-6-aminohexyl)-3-hydroxy-2-methylpyridin-4-one (CM1) and green tea extract on growth of Plasmodium falciparum. Malar J. (2015) 14:1-9. doi: 10.1186/s12936-015-0910-1

39. Shin S, Choi YM, Suh Y, Lee K. Delta-like 1 homolog (DLK1) inhibits proliferation and myotube formation of avian QM7 myoblasts. Comp Biochem Physiol B Biochem Mol Biol. (2015) 179:37-43. doi: 10.1016/j.cbpb.2014.09.006

40. Nihashi Y, Umezawa K, Shinji S, Hamaguchi Y, Kobayashi H, Kono T, et al. Distinct cell proliferation, myogenic differentiation, and gene expression in skeletal muscle myoblasts of layer and broiler chickens. Sci Rep. (2019) 9:1-15. doi: 10.1038/s41598-019-52946-4

41. Choi YM, Suh Y, Shin S, Lee K. Skeletal muscle characterization of Japanese quail line selectively bred for lower body weight as an avian model of delayed muscle growth with hypoplasia. PLoS ONE. (2014) 9:e95932. doi: 10.1371/journal.pone.0095932

42. Klasing KC. Nutrition and the immune system. Br Poult Sci. (2007) 48:52537. doi: $10.1080 / 00071660701671336$

43. Jiang Z, Schatzmayr G, Mohnl M, Applegate TJ. Net effect of an acute phase response-partial alleviation with probiotic supplementation. Poult Sci. (2010) 89:28-33. doi: 10.3382/ps.2009-00464

44. Broom LJ, Kogut MH. The role of the gut microbiome in shaping the immune system of chickens. Vet Immunol Immunopathol. (2018) 204:4451. doi: $10.1016 /$ j.vetimm.2018.10.002

45. Klasing KC. Nutritional aspects of leukocytic cytokines. J Nutr. (1988) 118:1436-46. doi: 10.1093/jn/118.12.1436

46. Ulluwishewa D, Anderson RC, McNabb WC, Moughan PJ, Wells JM, Roy NC. Regulation of tight junction permeability by intestinal bacteria and dietary components. J Nutr. (2011) 141:769-76. doi: 10.3945/jn.110. 135657

47. Song J, Xiao K, Ke YL, Jiao LF, Hu CH, Diao QY, et al. Effect of a probiotic mixture on intestinal microflora, morphology, and barrier integrity of broilers subjected to heat stress. Poult Sci. (2014) 93:581-8. doi: 10.3382/ps.2013-03455

48. Gadde U, Oh ST, Lee YS, Davis E, Zimmerman N, Rehberger T, et al. The effects of direct-fed microbial supplementation, as an alternative to antibiotics, on growth performance, intestinal immune status, and epithelial barrier gene expression in broiler chickens. Probiotics Antimicrob Proteins. (2017) 9:387-405. doi: 10.1007/s12602-017-9275-9

49. Lee KW, Kim DK, Lillehoj HS, Jang SI, Lee SH. Immune modulation by Bacillus subtilis-based direct-fed microbials in commercial broiler chickens. Anim Feed Sci Technol. (2015) 200:76-85. doi: 10.1016/j.anifeedsci.2014.12.006

50. Van Itallie CM, Fanning AS, Holmes J, Anderson JM. Occludin is required for cytokine-induced regulation of tight junction barriers. J Cell Sci. (2010) 123:2844-52. doi: $10.1242 /$ jcs.065581

Conflict of Interest: NZ, AS, and TR were employed by the Arm \& Hammer Animal and Food Production.

The remaining authors declare that the research was conducted in the absence of any commercial or financial relationships that could be construed as a potential conflict of interest.

Copyright ( 2021 Park, Goo, Nam, Wickramasuriya, Lee, Zimmerman, Smith, Rehberger and Lillehoj. This is an open-access article distributed under the terms of the Creative Commons Attribution License (CC BY). The use, distribution or reproduction in other forums is permitted, provided the original author(s) and the copyright owner(s) are credited and that the original publication in this journal is cited, in accordance with accepted academic practice. No use, distribution or reproduction is permitted which does not comply with these terms. 